\title{
Estimation of Efficiency of Bio- and Phytoremediation for Pesticides Contaminated Soil
}

\author{
Inna RASTIMESINA ${ }^{1}$, Svetlana TOLOCICHINA ${ }^{1}$, Olga POSTOLACHI ${ }^{1 *}$, Angela CINCILEI ${ }^{2}$, Nina STREAPAN ${ }^{1}$, \\ Vera MAMALIGA ${ }^{1}$ \\ ${ }^{1}$ Institute of Microbiology and Biotechnology, Academy of Sciences of Moldova; \\ ${ }^{2}$ The State Center for Certification and Registration of Phyto-sanitary Means and Fertilizers, Ministry of \\ Agriculture \\ *Corresponding author: oleseap@yahoo.com
}

Bulletin USAMV series Agriculture 72(2)/2015

Print ISSN 1843-5246; Electronic ISSN 1843-5386

DOI 10.15835/buasvmcn-agr: 11707

\begin{abstract}
Natural recovery of environmental pollution - natural attenuation, - is a long-term process. Development of a bioremediation technology for polluted soil is a multi-step process, which requires the integrated application of several methods: stimulation of the indigenous microflora in the contaminated site, and addition of microorganismdestructors to the soil. Recently at the final stages of soil remediation the method of phytoremediation is actively used. To estimate the efficiency of bioremediation of pesticides contaminated soil, using stimulation of anaerobic or facultative anaerobic microflora and phytoremediation applied afterwards. The soil was collected nearby the former destroyed storehouse of POPs. Pesticide residues in soil were evaluated using GC/MS multiresidue method, and the complex pollution of DDTs and trifluralin was found. With a view to remediate this complex contamination, the polluted soil was treated in combined aerobic and anaerobic conditions during 3.5 months, then the method of phytoremediation was used. The trifluralin content was reduced to $4-6 \%$ of the initial amount in all experimental variants as a result of bioremediation in anaerobic/aerobic conditions. Phytoremediation had not significant effect on trifluralin decomposition - only 2-3\%. Before phytoremediation DDT was decomposed on 27.5-29.0\%. After the phytoremediation, the degradation of pesticide amounted $56.3-72.5 \%$. This study has shown, that in the case of complex pollution, phytoremediation, as a method of supplementary remediation, was important for the decomposition of DDT and DDE, and it was not essential for the mineralization of DDD and trifluralin.
\end{abstract}

Keywords: bioremediation, DDT, pesticides, phytoremediation, trifluralin.

\section{INTRODUCTION}

Organochlorine pesticides have been used extensively all over the world for public health and agricultural purpose. Currently, their use is being phased out because of their toxicity, environmental persistence and accumulation in the food chain. Pesticides are usually applied simultaneously or one after another for crop protection, and this type of pesticide application often leads to combined contamination of these compound residues in the soil environment (Fuentes et al., 2010, 2013).
Natural recovery of environmental pollution - natural attenuation, - is a long-term process. The degree of pesticide stability under natural conditions depends on many factors: the climate, type, soil $\mathrm{pH}$, moisture and humus content, mechanical components, microflora, etc. The type and duration of the decomposition also are due to the chemical structure and stability of the pesticide (Phillips et al., 2004, 2005).

Remediation of contaminated sites can be achieved through physical (e.g. disposal in landfill, 
incineration), chemical (use of chemical oxidants) and biological processes. Biological treatment, commonly referred to as bioremediation, involves the breakdown of contaminants into non-toxic forms through the activities of microorganisms. Biostimulation of indigenous microbes through the addition of nutrients, coupled with frequent tilling has gained wide acceptance in biological cleanup of contaminated land. Biostimulation is sometimes combined with phytoremediation - the use of plants and their associated microorganisms for the in situ treatment of contaminated soil and sediment (Alkorta and Garbisu, 2001; Reichenauer and Germida, 2008). Recently, phytoremediation is actively used at the final stages of soil remediation (Pilon-Smits, 2005). Phytoremediation has the advantage of promoting ecological rehabilitation of contaminated land (Ayotamuno, 2009).

The Republic of Moldova has never produce pesticides, but the country still has frequent pollution accidents in the small spaces of the natural environment (water, soil). Despite the restrictions, considerably reducing the volume of pesticide in use, the problem related to environmental pollution in Republic of Moldova, including accidental pollution, remains acute. Currently over a thousand locations in the country - the former territories of pesticide deposits, reached the deplorable state - is a continuing source of pollution and threat to the environment and to human health in adjacent areas.

The management of domestic and hazardous wastes is considered as one of the most urgent environmental problems in Moldova. In Moldova, approximately 3,000 tons of obsolete pesticides were stored in various former collectiveagricultural warehouses or disposed in uncontrolled dumps (National Implementation Plan, 2004). The spatial analysis showed a strong pollution impact to surrounding agricultural territory near old pesticide storage (Bogdevich and Cadocinicov, 2007, 2009). Huge areas of contaminated soil around old storehouses represent a continuous danger for the environment and public health (The eliminators in Moldova, 2011). However, the information about the actual condition of soil after the repacking on former storages is not sufficient at present. This investigation is important also for the assessment of the remediation technologies that can be used for the soil detoxification in future.
Our goal was to estimate the efficiency of bioremediation of pesticides contaminated soil, using stimulation of anaerobic or facultative anaerobic microflora and further applying of phytoremediation.

\section{MATERIAL AND METHODS}

Destroyed storehouse for pesticides and organic fertilizers located near Sangera village, Chisinau municipality, the Republic of Moldova, has been selected using Management of Persistent Organic Pollutants (http://pops.mediu.gov.md/). Soil samples were collected at the site, were cleaned of roots and other impurities, sieved (mesh No. 2) and air-dried at $22-23^{\circ} \mathrm{C}$. Soil chemical and physical properties were determined using standard methods (Arinushkina, 1970; Kozlova, 2009).

The extraction of pesticide residues from soil has been performed in four repetitions per option according (Klisenko and Alexandrova, 1983). The determination of pesticide residues (PR) in soil was confirmed by gas chromatography with mass spectrometry GC/MS multiresidue method, at the gas chromatograph "Agilent Technologies" 6890N coupled with MSD mass selective detector "Agilent Technologies" 5973. Percentage of degradation was calculated according to Bento (Bento F. et al., 2003) using the expression: \% of degradation = [(PR control - PR experience) / PR control] ' 100; where $\mathrm{PR}$ is pesticide residue.

The bioremediation was established in the dark plastic jars, each containing $1,000 \mathrm{~g}$ of contaminated soil. The experiment was carried out in two main directions: strictly anaerobic conditions (Section 1) and alternating of anoxic / oxic conditions (Section 2). Contaminated soil without remediation was used as a control.

Section 1: creating of strictly anaerobic conditions by saturating the polluted soil with water up to $80 \%$ of water holding capacity (WHC), in the plastic jars sealed with Parafilm, in the dark and at temperature $22-24^{\circ} \mathrm{C}$. The soil was amended with mono- and disodium phosphate $(0.5 \%)$ and peptone $(1.0 \%)$ at the set up of the experiment (Variant 1).

Section 2: cycled anoxic and oxic conditions. Anaerobic conditions were created by saturating the contaminated soil with water $(80 \%$ of WHC) in the plastic jars sealed with Parafilm, and stored in the dark at $22-24^{\circ} \mathrm{C}$. At the beginning of the 
aerobic phase Parafilm has been removed, the soil mixed with a metal spatula and soil moisture was gradually brought up to $60 \%$ of WHC. At the start of each anaerobic phase mineral and organic (peptone) amendments were added to the soil, soil humidity was maintained at $80 \%$ of WHC. At the set up of the experiment the soil was amended with phosphates and peptone as indicated in Table 1.

At the beginning of each anaerobic phase the soil was amended with peptone and phosphates ( $0.2 \%$ each). For 2 variants (Variant 4 and 6) anaerobic phase lasted for 21 days, aerobic phase - for 14 days. At the beginning of each anaerobic phase the soil was amended with peptone and phosphates ( $0.2 \%$ each). At the beginning of each aerobic phase the soil was amended with glucose $(0.5 \%)$.

The duration of anoxic (anoxic / oxic) phase was 105 days, and then the experiment was passing to the oxic phase followed by stimulation of microorganisms by applying sawdust, phytoremediation with oat Avena sativa L. (Va- riant 1, 2, 5, and 6) or alfalfa Medicago sativa $L$. (Variant 3 and 4), for 55 days. Monthly plants were cut, mixed with the soil and new seeds were planted.

\section{RESULTS AND DISCUSSION}

Considering physical and chemical properties of the collected soil, the soil type was classified as carbonated chernozem. Analytical data indicated, that the studied site was longterm and complex polluted by pesticides (Tab. 2 ). The major component of contamination was dinitroaniline herbicide trifluralin and the minor component was organochlorine insecticide DDT and its metabolites DDE and DDD (DDTs); the total content of pesticides was $21.5 \mathrm{mg} / \mathrm{kg}$ dry soil.

According to our previous studies, the soil moisture maintained at $60 \%$ of WHC for 135 days without further treatment - tilling, fertilization, any amendments, leads to degradation of slightly more than 7\% trifluralin and 5\% DDTs (Rastimesina et al., 2014). Creating anaerobic

Tab. 1 Treatment protocol for soil bioremediation in laboratory conditions

\begin{tabular}{|c|c|c|c|c|c|c|c|c|c|}
\hline \multirow[b]{3}{*}{ 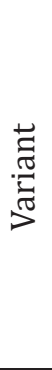 } & \multicolumn{7}{|c|}{ Biostimulation } & \multicolumn{2}{|c|}{ Phytoremediation } \\
\hline & \multirow{2}{*}{ 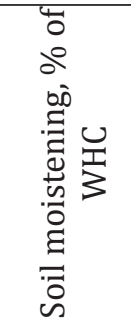 } & \multirow{2}{*}{ 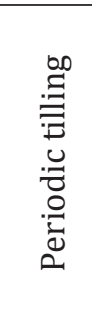 } & \multicolumn{5}{|c|}{ Amendments, \% } & \multirow{2}{*}{ 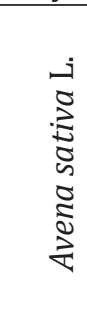 } & \multirow{2}{*}{ 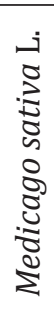 } \\
\hline & & & 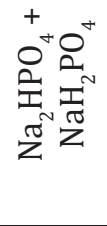 & 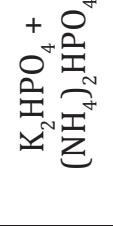 & 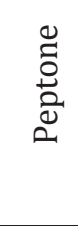 & 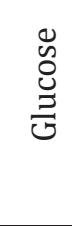 & 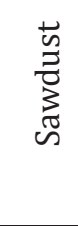 & & \\
\hline 1 & 80 & - & 0.5 & - & 1.0 & - & \multirow{6}{*}{6.0} & + & - \\
\hline 2 & $80 / 60$ & $-/+$ & 0.5 & - & 1.0 & - & & + & - \\
\hline 3 & $80 / 60$ & $-/+$ & - & 0.5 & 1.0 & - & & - & + \\
\hline 4 & $80 / 60$ & $-/+$ & - & 0.5 & 0.5 & 0.5 & & - & + \\
\hline 5 & $80 / 60$ & $-/+$ & - & 1.0 & 0.5 & - & & + & - \\
\hline 6 & $80 / 60$ & $-/+$ & - & 1.0 & 0.5 & 0.5 & & + & - \\
\hline
\end{tabular}

Tab. 2 The level of soil contamination with pesticides (storehouse near Sangera) before the bioremediation, $\mathrm{mg} / \mathrm{kg}$ dry soil

\begin{tabular}{|c|c|c|c|c|c|c|}
\hline \multirow{2}{*}{ Trifluralin } & \multirow{2}{*}{$\sum$ DDTs } & \multirow{2}{*}{$\mathrm{p}, \mathrm{p}^{\prime}-\mathrm{DDT}$} & \multicolumn{2}{|c|}{ DDD } & \multicolumn{2}{|c|}{ DDE } \\
\hline & & & o,p'-DDD & $\mathrm{p}, \mathrm{p}^{\prime}-\mathrm{DDD}$ & $0, p^{\prime}-D D E$ & $p, p^{\prime}-D D E$ \\
\hline \multirow{2}{*}{$19.67 \pm 0.31$} & \multirow{2}{*}{1.82} & \multirow{2}{*}{$0.37 \pm 0.010$} & $0.28 \pm 0.006$ & $0.51 \pm 0.008$ & $0.24 \pm 0.012$ & $0.42 \pm 0.007$ \\
\hline & & & \multicolumn{2}{|c|}{$0.79 \pm 0.014$} & \multicolumn{2}{|c|}{$0.66 \pm 0.019$} \\
\hline
\end{tabular}


conditions by saturation of soil with water up to $80 \%$ of WHC allowed increasing the degradation of trifluralin to $25 \%$ and DDTs - up to $28 \%$ of the initial concentration (Rastimesina et al., 2014). The improving in efficiency of pesticides degradation in soil can be achieved using mineral and organic amendments in modeling anoxic and anoxic / oxic conditions.

After 3.5monthsofthesetting of bioremediation experiment, soil analysis was performed. The data of analysis were used to estimate the contribution of soil treatment in anaerobic and alternating anaerobic-aerobic conditions and the role of subsequent phytoremediation in pesticides degradation.

In all experimental variants, DDTs degradation in soil was at the same level and amounted 58.6$64.9 \%$, regardless of the method of soil treating, amendments and their concentration (Fig. 1) The data obtained after phytoremediation shown a decrease in DDTs concentration at the variants amended with sodium phosphates to $69.4-69.7 \%$,

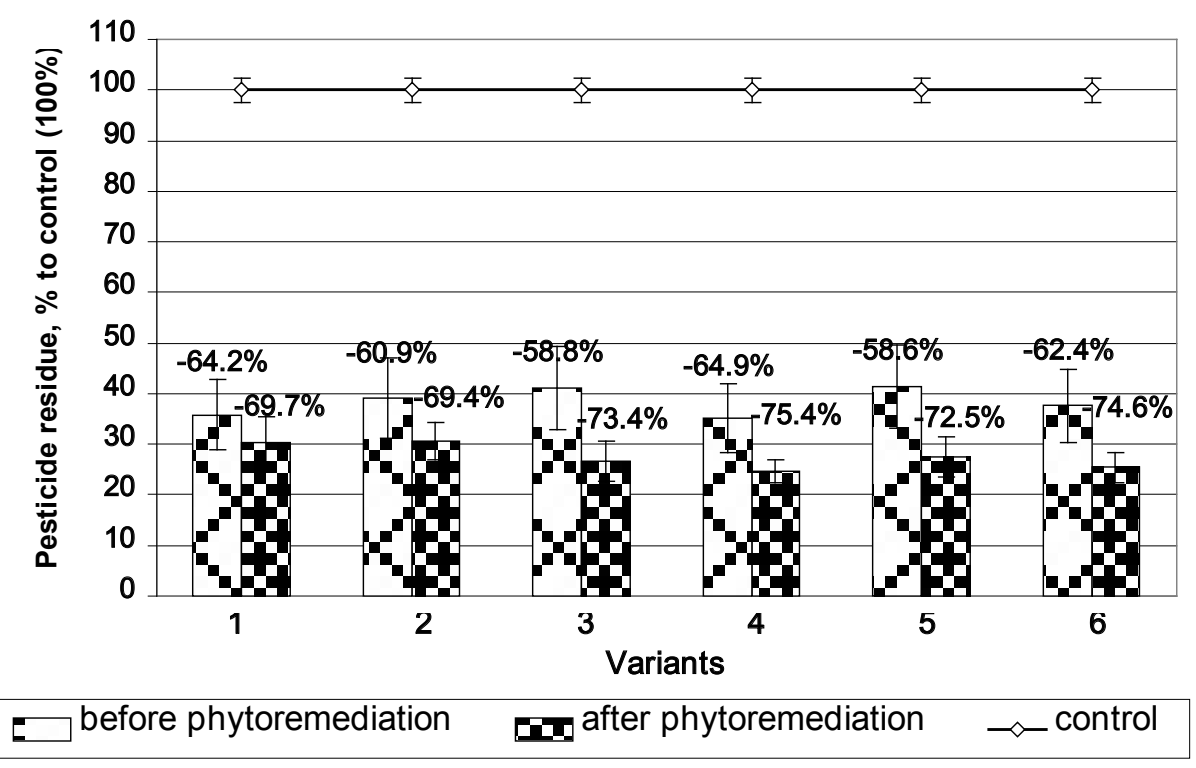

Fig. 1. Residue of DDTs metabolites in soil before and after the phytoremediation

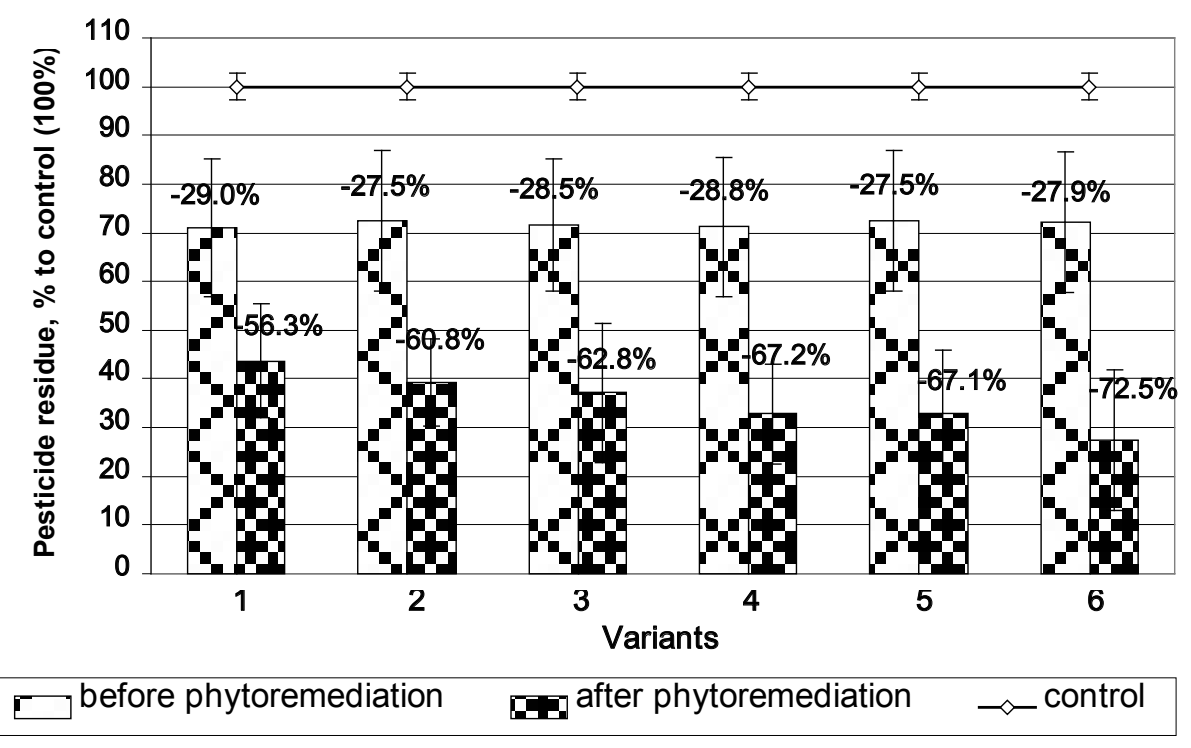

Fig. 2. Pesticide DDT pesidue in soil before and after the phytoremediation 
on 5.5-8.6\%, while at the variants amended with potassium and ammonium phosphates to 72.5$75.4 \%$, the contribution of phytoremediation was 10.5-14.6\%.

Amount of DDT, decomposed before the phytoremediation was not significant, the degradation was less than one third of the initial concentration - 27.5-29.0\%. After phytoremediation, pesticide degradation ranged from $56.3 \%$ in variant 1 from anoxic Section to
$72.5 \%$ in variant 6 from anoxic / oxic Section (Fig. 2).

On the first stage of experiment it was degraded 78.0-78.8\% of DDD. Analysis showed complete disappearance of the o,p-DDD isomer and significant decrease in the concentration of p,p-DDD isomer. Phytoremediation did not influence the further degradation of this metabolite; degradation in the final stage was 78.1-79.5\%. Perhaps, during the experiment, there

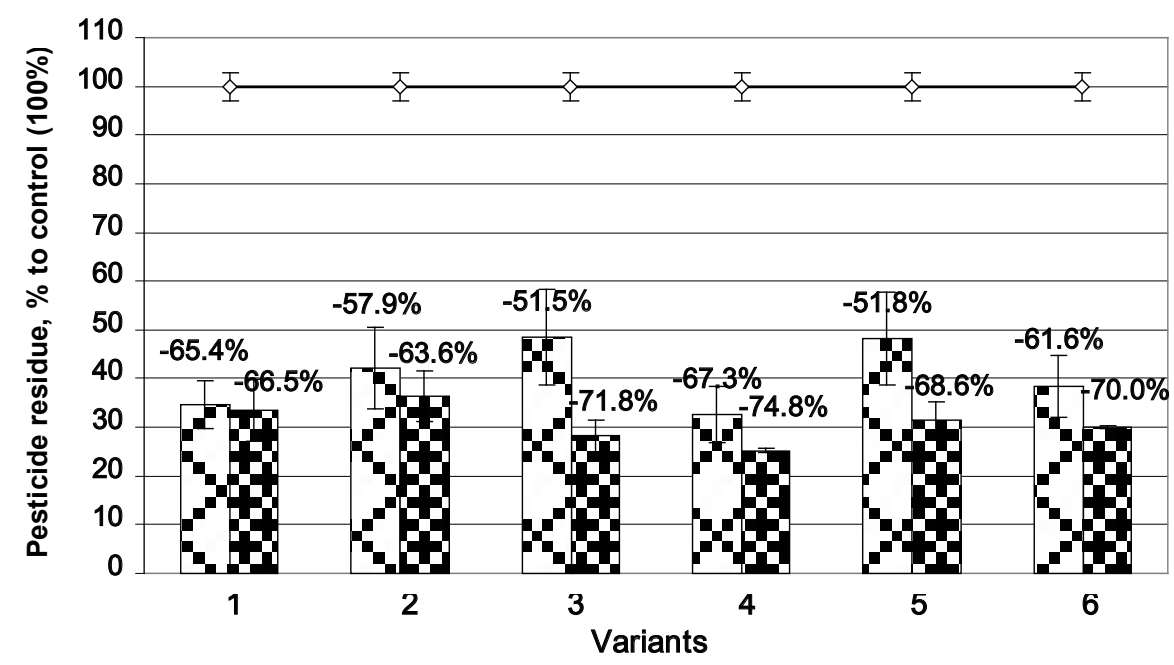

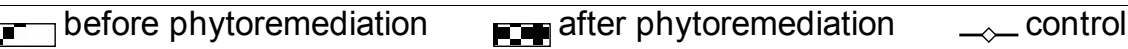

Fig. 3. Metabolite DDE pesidue in soil before and after the phytoremediation

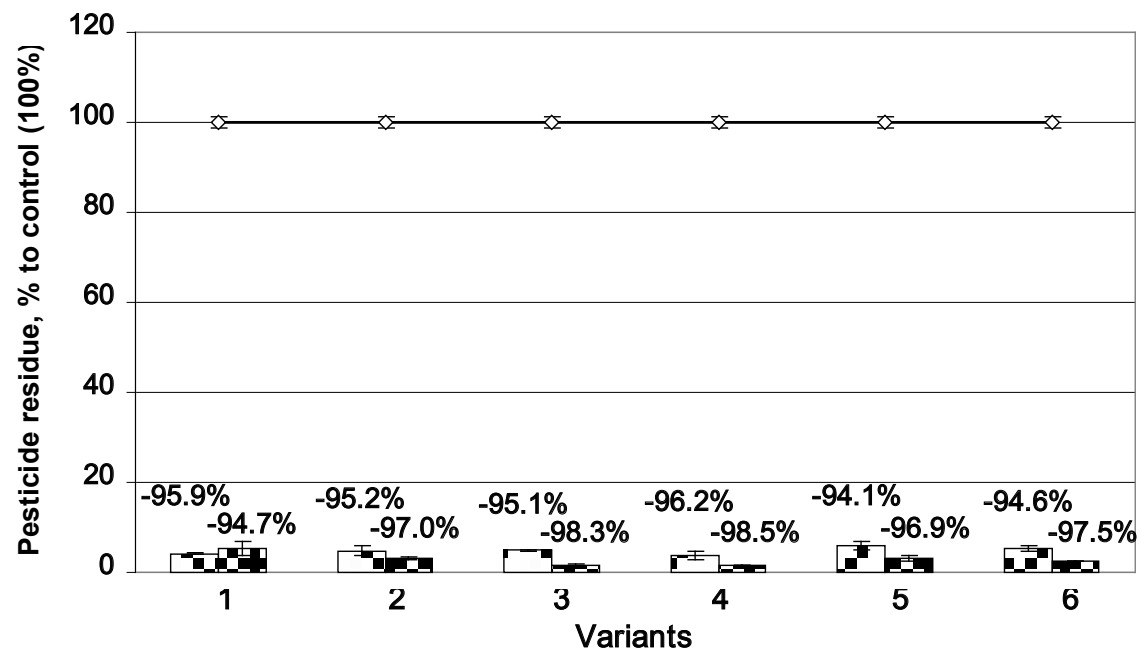

before phytoremediation $\quad$ G after phytoremediation $\leadsto$ control

Fig. 4. Trifluralin mineralization in soil before and after the phytoremediation 
was a gradual accumulation and decomposition of DDD, the product of the anaerobic decomposition of DDT.

Regarding DDE degradation, the most favorable conditions were created in variant 4 , where anoxic conditions were alternated with oxic ones, amended with glucose at the beginning of each aerobic phase.

Before the phytoremediation, in variants 2,3 , and 5 was degraded more than half of the initial amount of the metabolite DDE; in variants 1,6 , and 4 DDE degradation amounted 61.6-67.3\%. After phytoremediation the degradation of this metabolite reached $74.8 \%$ (variant 4 ); the most significant contribution of phytoremediation 16.8-20.3\%, - could be noticed in variants 3 and 5, without glucose amendment (Fig. 3).

Analysis of soil samples showed that almost complete mineralization of trifluralin in all the variants was obtained (Fig. 4). The degradation of the herbicide was 94.1-96.2\%. Further degradation of trifluralin as a result of phytoremediation was insignificant $-1.8-3.2 \%$. The most complete mineralization of trifluralin, $98.5 \%$, took place in the variant 4 .

\section{CONCLUSION}

Thus, we can conclude, that DDTs degradation process has been established in all experimental variants. The metabolite DDD, from all of the DDT metabolites, has degraded mostly; the analyzes showed complete disappearance, p-DDD isomer and a significant reduction in the concentration of p, p-isomer DDD.

In the case of integrated, complex pollution, phytoremediation, as an additional way of remediation, was important for the elimination of DDT and DDE, but it was not essential for the mineralization of DDD and trifluralin.

\section{REFERENCES}

1. Alkorta I, Garbisu C (2001). Phytoremediation of organic contaminants in soils. Bioresour Technol 79(3):273-276.

2. Arinushkina EV (1970). Guidance on chemical analysis of soils. 2nd ed., Moscow: MGU: 488.

3. Ayotamuno JM, Kogbara RB, Agoro OS (2009). Biostimulation supplemented with phytoremediation in the reclamation of a petroleum contaminated soil. World J Microbiol Biotechnol 25:1567-1572.
4. Bento FM, Camargo FAO, Okeke B, Frankenberger JrWT (2003). Bioremediation of soil contaminated by diesel oil. Brazilian Journal of Microbiology 34(1):65-68.

5. Bogdevich 0, Cadocinicov O (2007). Assessment of pesticide pollution in frame of old pesticide storage and surrounding territory (Balceana case study). $9^{\text {th }}$ International $\mathrm{HCH}$ and Pesticides Forum for CEECCA Countries "Obsolete Pesticides in Central and Eastern European, Caucasus and Central Asia Region" Chisinau: 279-284.

6. Bogdevich O, Cadocinicov O (2009). Elimination of acute risks from obsolete pesticides in Moldova: phytoremediation experiment at a former pesticide storehouse. Application of Phytotechnologies for Cleanup of Industrial, Agricultural and Wastewater Contamination. NATO book series. C. Environmental Security. Springer: 61-87.

7. Fuentes MS, Benimeli CS, Cuozzo SA, Saez JM, Amoroso MJ (2010). Microorganisms capable to degrade organochlorine pesticides. Current Research, Technology and Education Topics in Applied Microbiology and Microbial Biotechnology. Ed.: FORMATEX: 1255-1264.

8. Fuentes MS, Briceño GE, Saez JM, Benimeli CS, Diez MC, Amoroso MJ (2013). Enhanced removal of a pesticides mixture by single cultures and consortia of free and immobilized Streptomyces strains. Biomed Res Int 2013: 9. ID 392573.

9. Klisenko MA, Alexandrova LG (1983). Determination of pesticide residues. Kundiev YuI, eds., Kiev: Health: 174.

10. Kozlova AA (2009). The educational practice on soil physics: methodical handbook. Irkutsk: Irkutsk University Pressp: 52-53.

11. Phillips TM, Lee H, Trevors JT, Seech AG (2004). Mineralization of hexachlorocyclohexane in soil during solid-phase bioremediation. J Ind Microbiol Biotechnol Springer: 31:216-222.

12. Phillips TM, Seech AG, Lee H, Trevors JT (2005). Biodegradation of hexachlorocyclohexane $(\mathrm{HCH})$ by microorganisms. Biodegradation 16:363-392.

13. Pilon-Smits EAH (2005). Phytoremediation. Annu Rev Plant Biol 56:15-39.

14. Rastimesina I, Postolachi O, Cincilei A, Tolocichina S, Streapan N, Mamaliga V (2014). New strategies for bioremediation of soil contaminated by obsolete pesticides in the Republic of Moldova. Oltenia Journal for Studies in Natural Sciences. 30(1):198-201.

15. Rastimesina I, Cincilei A, Postolachi 0, Tolocichina S, Mamaliga V, Streapan N (2014). Approaches for bioremediation of pesticide contaminated soil: complex pollution problems. Scientific papers. Horticulture. 57(1):301-306.

16. Reichenauer TG, Germida JJ (2008). Phytoremediation of organic contaminants in soil and groundwater. Chem Sus Chem 1:708-717. 
17. Republic of Moldova. National Implementation Plan for the Stockholm Convention on Persistent Organic Pollutants. Ministry of Ecology and Natural Resources. (2004). World Bank, Edit. Stiinta, Chisinau: 80 pp. Available online at: http://www.pops.int/documents/ implementation/nips/submissions/moldova.pdf (accessed March 29, 2014).
18. The Eliminators in Moldova. (2011). GEF/FAO project Capacity Building on Obsolete and POPs Pesticides in Eastern European, Caucasus and Central Asian Countries (EECCA). Brochure: 46. Available online at: http:// milieukontakt.net/en/wp-content/uploads/2011/10/ The-Eliminators-in-Moldova-obsolete-pesticides. PDF (accessed: March 29, 2014). 